\title{
PRESCRIÇÃO DE ANTIBIÓTICOS DE USO HUMANO PARA FINS DE TERAPIA ANIMAL
}

Maria Eduarda Canôa Bertão; Daniel Andrade da Silva; Willian Marinho Dourado Coelho

${ }^{1}$ Fundação Eduucacional de Andradina - FEA, Faculdades de Ciências Agrárias de Andradina - FCAA, Curso de Medicina Veterinária, Andradina, SP. E- mail: mariaeduarda bertao@hotmail.com

\section{RESUMO}

O estudo exposto tem por objetivo quantificar prescrições de antibacterianos humanos voltado à terapia animal. Deu início em 01 de Abril de 2017 a 30 de Setembro de 2017, realizado nas cidades de Andradina-SP, Castilho- SP, Inocência-MS, Nova Independência- SP e Três Lagoas-MS, contou com cooperação de quatorze drogarias nas respectivas cidades, que contribuíram para preenchimento de formulário composto de dados do estabelecimento e antibióticos prescritos por Médicos Veterinários, estas foram recolhidas uma vez ao mês (Fig. 1),listados em princípios ativos, contabilizando Doxiciclina 23,7 \%, Cefalexina 16,2\%, Rifamicina 14,4\%, Sufametoxazol+ Trimetropim 9,27 \%, Tobramicina 7,9\%, Metronidazol 6,9\%, Cloranfenicol 4,8\%, Neomicina 3,86\%, Ciprofloxacino 3,6\%, Amoxicilina 2,31\%, Gentamicina 2,0\%, Gatilfloxacino 1,3\%, Ampicilina, Azitromicina, Ceftriaxona, Norfloxacino 0,51\%, Bacitracina, Cefadroxila, Moxifloxacino, Nitrofural, Ofloxacino e Terramicina 0,25\% (Tab.1). Conclui-se, insatisfatório o conhecimento dos princípios gerais dos antibióticos sem acompanhamento terapêutico e utilização de forma irracional do mesmo.

Palavras-chave: antibacterianos, farmácia, medicamentos, racional, saúde.

\section{PRESCRIPTION OF ANTIBIOTICS FOR HUMAN USE FOR PETTHERAPY}

\begin{abstract}
The objective of this study was to quantify human antibacterial prescriptions for animal therapy. It began on April 1, 2017 to September 30, 2017, in the cities of Andradina-SP, Castilho-SP, Inocência-MS, Nova Independência-SP and Três Lagoas-MS, with the cooperation of fourteen drugstores in the respective cities, which contributed to the completion of a form composed of data from the establishment and antibiotics prescribed by Veterinary Doctors, were collected once a month (Fig. 1), listed in active principles, accounting for Doxycycline $23.7 \%$, Cephalexin $16.2 \%$ Rifamycin 14.4\%, Sufamethoxazole + Trimetropim 9.27\%, Tobramycin 7.9\%, Metronidazole 6.9\%, Chloramphenicol 4.8\%, Neomycin 3.86\%, Ciprofloxacin 3.6\%, Amoxicillin 2.31\%, Gentamicin 2.0\%, Gatilfloxacin 1.3\%, Ampicillin, Azithromycin, Ceftriaxone, Norfloxacin 0.51\%, Bacitracin, Cefadroxil, Moxifloxacin, Nitrofural, Ofloxacin and Terramycin $0.25 \%$ (Tab.1). It is concluded that the knowledge of the general principles of antibiotics without therapeutic follow-up and irrational use of antibiotics is unsatisfactory.
\end{abstract}

Keywords: antibacterial, pharmacy, drugs, rational, health.

\section{INTRODUÇÃO}

Os antibacterianos podem ter sua origem natural ou sintética, agindo diretamente na morte da bactéria ou inibindo a sua reprodução, denominadas assim bactericidas ou 
bacteriostáticos, sendo utilizados somente se houver evidências clínicas ou laboratoriais de infecção bacteriana (Schlecht ,2018; Walsh, 2003).

Contudo, a escolha da droga eficaz para o tratamento, baseia-se em culturas e antibiogramas considerando os microrganismos infectantes mais prováveis, diminuindo assim efeitos colaterais e resistência bacteriana, porem há infecções que requerem intervenção cirúrgica, pois não respondem a antibióticos isolados (Schlecht,2018).

$\mathrm{Na}$ rotina Clínica de Pequenos Animais, são utilizados medicamentos da linha humana devido à grande aplicabilidade dos princípios ativos e formas farmacêuticas, assim como, medicamentos específicos para uso veterinário prescritos na vigência de um quadro infeccioso ou quando indicado profilaticamente (Anvisa, 2010; Anvisa,2010).

O objetivo desse estudo foi quantificar prescrições de antibacterianos de uso humano para terapia animal nas cidades de Andradina- SP, Castilho- SP, Inocência- MS, Nova Independência- SP e Três Lagoas- MS.

\section{MATERIAL E MÉTODOS}

O estudo iniciou-se em 1 de Abril de 2017 a 30 de Setembro de 2017, contou com a colaboração de 14 (quatorze) drogarias em cinco cidades sendo estas Andradina- SP, Castilho- SP, Inocência- MS, Nova Independência- SP e Três Lagoas- MS, estas contribuíram com o preenchimento de uma ficha identificada que continha seu nome comercial, cidade, endereço e mês, onde deveria ser preenchida com os antibióticos prescritos por Médicos Veterinários (Fig. 1). Os dados eram coletados uma vez a cada 30 (trinta) dias e classificadas de acordo com a classe farmacológica.

Figura 1. Ficha mensal confeccionada para o estudo

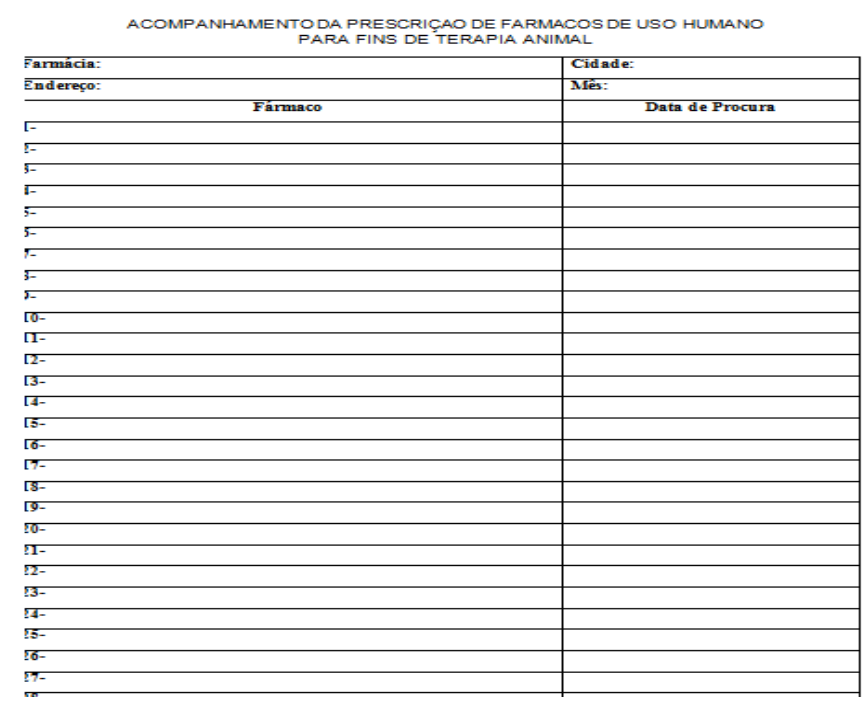

\section{RESULTADOS E DISCUSSÃO}

Durante todo o estudo foram receitados 388 (trezentos e oitenta e oito) antibióticos, estes classificados de acordo com seu princípio ativo, os mais prescritos foram Doxiciclina com 23,7 \% (92/388), Cefalexina 16,2\% (63/388), Rifamicina 14,4\% (56/388), Sufametoxazol+ Trimetropim 9,27\% (36/388), Tobramicina 7,9\% (31/388), Metronidazol 6,9\% ( 27/388), Cloranfenicol 4,8\% (19/388), Neomicina 3,86\% (15/388), Ciprofloxacino 3,6\% (14/388), Amoxicilina 2,31\% (9/388), Gentamicina 2,0\% (8/388), Gatilfloxacino com 1,3\% (4/388), Ampicilina, Azitromicina, Ceftriaxona e Norfloxacino encontraram-se empatados com, 0,51\% (2/388) e Bacitracina, Cefadroxila Moxifloxacino, Nitrofural, Ofloxacino e Terramicina com menor número de $0,25 \%(1 / 388)$ respectivamente ( tab. 1). 
Tabela 1. Quantidade de Antibióticos prescritos durante o estudo

\begin{tabular}{|c|c|c|c|c|c|c|c|}
\hline & Abril & Maio & Junho & Julho & Agosto & Setembro & Total \\
\hline Doxiciclina & 16 & 14 & 14 & 15 & 16 & 17 & 92 \\
\hline Cefalexina & 20 & 9 & 9 & 6 & 8 & 11 & 63 \\
\hline Rifamicina & 16 & 12 & 4 & 8 & 8 & 8 & 56 \\
\hline $\begin{array}{l}\text { Sulfametoxazol } \\
\text { Trimetropim } \\
\end{array}$ & +8 & 8 & 4 & 6 & 6 & 4 & 36 \\
\hline Tobramicina & 5 & 7 & 7 & 5 & 1 & 6 & 31 \\
\hline Metronidazol & 2 & 1 & 4 & 7 & 5 & 8 & 27 \\
\hline Cloranfenicol & --- & --- & 4 & --- & 8 & 7 & 19 \\
\hline Neomicina & 1 & 3 & 2 & 3 & 3 & 3 & 15 \\
\hline Ciprofloxacino & 1 & 2 & 1 & 2 & 3 & 5 & 14 \\
\hline Amoxicilina & 2 & --- & 1 & 3 & 1 & 2 & 9 \\
\hline Gentamicina & --- & 4 & 1 & 1 & 1 & 1 & 8 \\
\hline Gatilfloxacino & --- & 1 & -- & --- & 1 & 2 & 4 \\
\hline Ampicilina & 2 & --- & --- & --- & --- & --- & 2 \\
\hline Azitromicina & --- & 1 & --- & --- & 1 & --- & 2 \\
\hline Ceftriaxona & --- & 2 & --- & --- & --- & --- & 2 \\
\hline Norfloxacino & --- & --- & --- & 2 & --- & --- & 2 \\
\hline Bacitracina & --- & 1 & --- & --- & --- & --- & 1 \\
\hline Cefadroxila & 1 & --- & --- & --- & --- & --- & 1 \\
\hline Moxifloxacino & --- & --- & --- & 1 & --- & --- & 1 \\
\hline Nitrofural & 1 & -- & -- & --- & --- & --- & 1 \\
\hline Ofloxacino & --- & 1 & --- & --- & --- & --- & 1 \\
\hline Terramicina & --- & -- & 1 & --- & --- & --- & 1 \\
\hline Total Mês & 75 & 66 & 52 & 59 & 62 & 74 & 388 \\
\hline
\end{tabular}

Figura 1. Procura de Antibióticos

\section{Procura de Antibióticos}

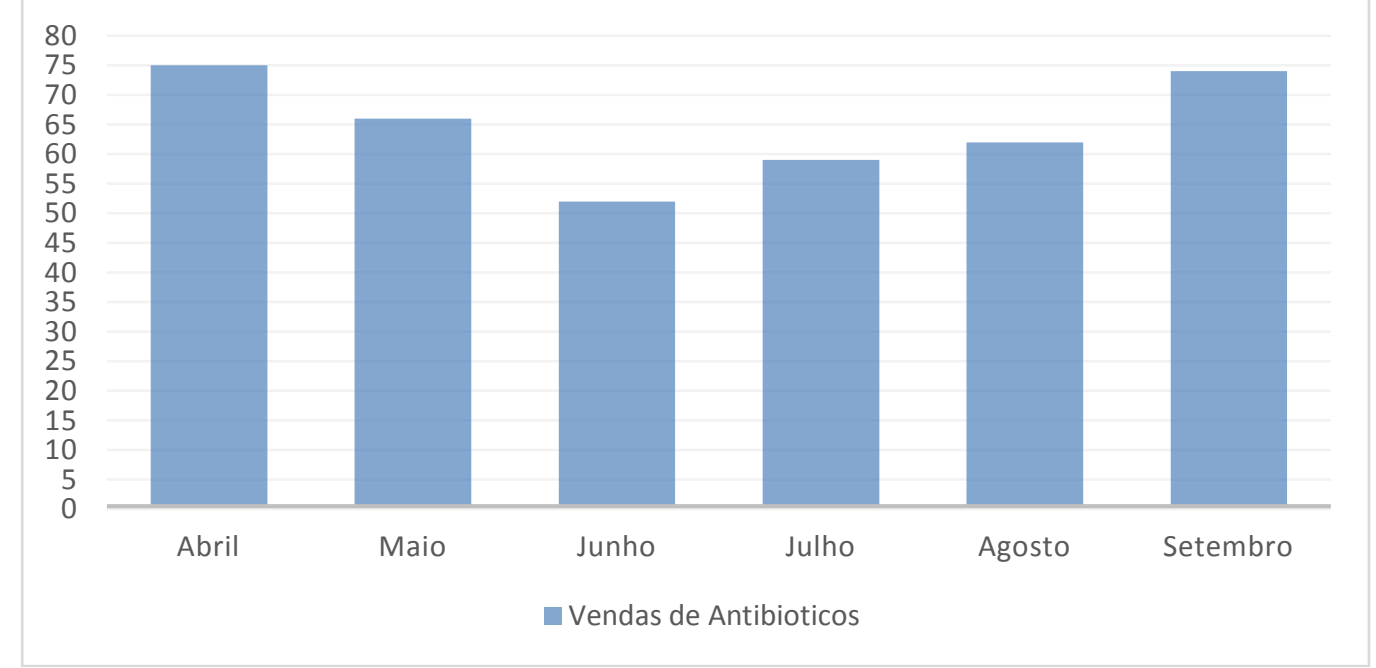


RDC no 20/2011 diz que apesar da escassez de fármacos no mercado brasileiro, com a diversidade encontrada no nosso estudo de diferentes antibióticos prescritos, promoverá uma melhor relação risco-benefício para o paciente e a sociedade, não apenas pelo uso relacionado a emergência e cepas de bactérias resistentes, mas sim com a elevação dos custos (Anvisa,2007).

Segundo CRMV,2016, o profissional deve prescrever o tratamento que considere mais indicado, utilizando recursos ou materiais que julgar necessários, levando em consideração características do paciente, o tipo de bactéria a ser tratada e suas propriedades (Anvisa,2007).

Portanto, o resultado do estudo de prescrição de antibióticos de uso humano para fins de terapia animal é confirmatório, desde que, a prescrição seja com receituário de controle especial em duas vias, contendo dados do tutor e paciente, que será retida para fins de fiscalização do estabelecimento comercial (RDC $n$ ㅇ 20/2011).

\section{CONCLUSÃO}

O conhecimento dos princípios gerais do uso de antibacterianos, assim como suas propriedades e características básicas disponíveis no mercado, é fundamental para o desenvolvimento de novas opções terapêuticas para o tratamento adequado.

\section{REFERÊNCIAS}

ANVISA. Agencia Nacional de Vigilância Sanitária. Semana Mundial de uso consciente de antibióticos. Brasília, 13 de Novembro de 2017. http://portal.anvisa.gov.br/antibioticos

ANVISA. Antimicrobianos. Bases teórica e uso clinico. Brasília, 2007. http://www.anvisa.gov.br/servicosaude/controle/rede $\mathrm{rm} / \mathrm{cursos} / \mathrm{rm}$ controle/opas web/modul o1/conceitos.htm.

ANVISA. Diretoria Colegiada da Agencia Nacional de vigilância Sanitária. Resolução da Diretoria Colegiada - RDC № 44, de 2010. Controle de medicamentos à base de substâncias classificadas como antimicrobianos, de uso sob prescrição médica, isoladas ou em associação e dá outras $\begin{array}{lllll}\text { providências, } & \text { Brasília. } & 20 & \text { de } & \text { Outubro } \\ \end{array}$ http://www.cff.org.br/userfiles/file/noticias/RDC\%20ANVISA\%20No\%20\%2044\%20DE\%2026\%20D E\%20OUTUBRO\%20DE\%202\%20010\%20CONTROLE\%20DE\%20ANTIMICROBIANOS.pdf.

ANVISA. Orientações de procedimentos relativos ao controle de medicamentos à base de substâncias classificadas como antimicrobianos, de uso sob prescrição isoladas ou em associação.

NOTA TÉCNICA SOBRE A RDC N 20/2011. Brasília 24 de Setembro de 2013. http://www.anvisa.gov.br/sngpc/documentos\%202013/Nota Tecnica RDC n 20201124092 013.pdf.

ANVISA. Referências técnicas para atividades veterinárias. REFERÊNCIA TÉCNICA PARA FUNCIONAMENTO DOS SERVIÇOS VETERINÁRIOS. Brasília 04 de Março de 2010. http://portal.anvisa.gov.br/documents/33856/2054354/Refer\%C3\%AAncia+t\%C3\%A9cnica+para+ o+funcionamento+dos+servi\%C3\%A7os+veterin\%C3\%A1rios/057287c3-823e-41aa-a121$\underline{672 \mathrm{~cd} 54 \mathrm{faaa} 8 .}$

CRMV. Decreto-lei no 5.517, de 16 de Dezembro de 2016. Lex: Código de ética do Médico Veterinário: edição federal, Brasília, DF, 16 dez. 2016. Seção 1, p.14. http://portal.cfmv.gov.br/lei/index/id/508 
SCHLECHT H.P. Manual MSD. Versão para profissionais da saúde. Visão geral dos antibacterianos. Kenilworth, 2018. $\quad$ https://www.msdmanuals.com/pt-br/profissional/doen\%C3\%A7asinfecciosas/bact\%C3\%A9rias-e-drogas-antibacterianas/vis\%C3\%A3o-geral-dos-antibacterianos.

WALSH, C.; Antibiotics: Actions, Origins, Resistence, ASM Press: Washington, 2003. https://doi.org/10.1128/9781555817886 